\title{
Narrativa(s) en ficción televisiva y cinematográfica
} Sergio Cobo-Durán y Javier Lozano Delmar

ReaDuck, 2020 ISBN: 9788412011999 249 páginas

Sofía Otero Escudero sofoteesc@gmail.com Universidad de Sevilla

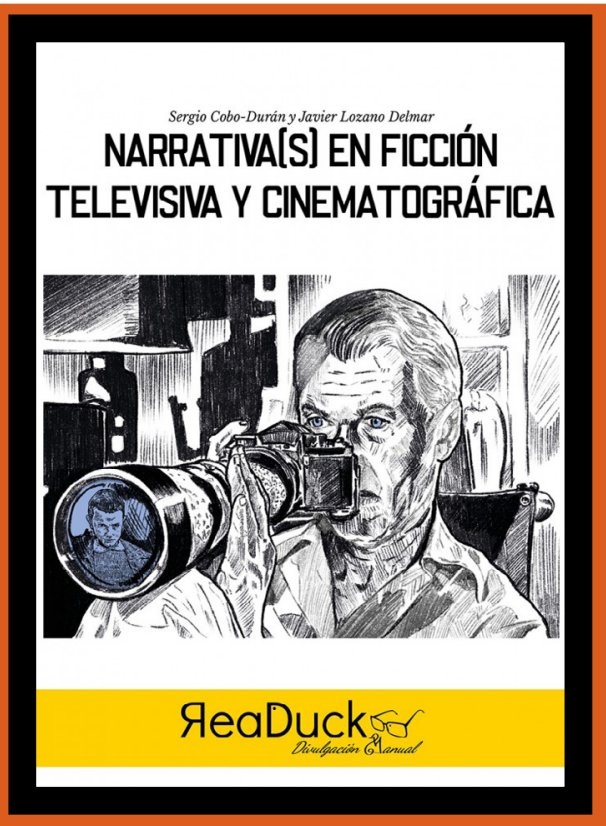

El groso de trabajos académicos que han abordado a lo largo de la historia la narrativa en ficción es tan extenso, que se torna tarea complicada como lector/a y especialmente como docente y estudiante, el repasar toda la bibliografía para poder profundizar y entender todos los conceptos y teorías existentes. En el libro Narrativa(s) en ficción televisiva y cinematográfica, los docentes universitarios Sergio Cobo-Durán y Javier Lozano Delmar emprenden la ardua tarea de escribir y reflexionar sobre las narrativas en ficción, dando lugar a un didáctico y fructífero manual divulgativo con el objetivo de enseñar de forma más sencilla, algo tan complejo y a su vez hermoso en el mundo audiovisual como es la narrativa.

Los autores construyen un contenido sencillo y rico, convirtiendo la lectura en un viaje agradable por los distintos pilares que conforman hoy en día la narración en ficción de cine y televisión. Para hacer más accesible dicho viaje, los textos del libro se acompañan de unas originales ilustraciones esbozadas en blanco y negro, realizadas por José Antonio González Padilla.

El texto se divide de forma precisa y ordenada en seis bloques, a su vez desglosados en varios epígrafes incluyendo casos prácticos y autoevaluaciones para el estudiantado, así como entrevistas en alguno de ellos. Esta estructura se ve enriquecida además por un párrafo introductorio en cada bloque donde se presentan los objetivos para el aprendizaje.

Para dar comienzo al libro, a través de las palabras del narrador Fernando Iwasaki, se hace una reflexión breve sobre el oficio. "Narrar supone un proceso que consiente la existencia de un 'punto ciego'; es decir, un espacio de ambigüedad donde el lectorespectador se apodera de la obra que lee o contempla". (Cobo-Durán \& Lozano Delmar, 2020, 12).

Tras esta introducción, en el primer bloque se presenta el contexto y marco teórico que aportan los conocimientos necesarios para sumergirse de lleno en la narración audiovisual. Se desgranan de forma ordenada conceptos esenciales y complejos como la diégesis - y sus tipos -, o el transmedia, con una redacción clara y asequible, sin dejar 
de lado la riqueza de referencias teóricas y cinematográficas. Referencias que suelen centrarse en producciones cercanas a la audiencia más actual como Stranger Things o Juego de Tronos, pero recurriendo también a grandes clásicos como Nosferatu (1922) o La Ventana Indiscreta (1954). Esta obra maestra de Alfred Hitchcock funciona además como portada del libro, elección que no es casual dado que dicho filme es uno de los referentes para los manuales de narrativa en ficción - David Bordwell incluso dedica un capítulo completo a su análisis en La Narración en el cine de ficción (1996)-.

El resto de los bloques que prosiguen, se presentan como los engranajes necesarios para hacerfuncionar la narrativa audiovisual. En primer lugar, se define la transtextualidad y sus tipos, reflexionando sobre la conexión existente entre los textos de ficción. Contenido que se enriquece con una entrevista a la investigadora y docente Irene Raya.

A continuación, se enumeran y explican los componentes más importantes de la narración, como el tiempo y el espacio del discurso, el punto de vista y la enunciación o los existentes del relato - personajes y ambientes -. Dentro del bloque de los existentes del relato, se desarrolla un análisis de caso sobre el cortometraje La dama y la muerte (Javier Recio, 2010), donde se aplican de forma práctica las teorías explicadas sobre el análisis actancial de Greimas (1983).

Para finalizar el manual y siguiendo un orden temporal lógico, Sergio Cobo-Durán y Javier Lozano Delmar exploran las nuevas tendencias en la narración audiovisual. Abordan cuatro aspectos claves para entender la evolución de las nuevas formas narrativas e invitan a la persona que lee a revisar y ampliar las categorías propuestas. Además, añaden en sus últimas páginas una serie de recursos y bibliografía para mantenerse al día. Desde un punto de vista crítico y analítico, los autores ponen el broche final compartiendo una mirada abierta a nuevas formas, invitando así a continuar aprendiendo desde las revisiones y lecturas sobre la(s) narrativa(s) en ficción.

Como conclusión y volviendo al cold open, hay tres ideas fundamentales que giran en torno al manual Narrativa(s) en ficción televisiva y cinematográfica; ideas que el docente Pablo Nacach menciona en Amor Maestro: ser autodidacta, practicar y aprender. "El juego del fútbol (no confundir con 'el fútbol') también ha hecho las veces de maestro en mi relación con la escritura: 'se juega como se entrena' es una máxima imperiosa para entender que sin la (auto)disciplina del entrenamiento no hay textualidad", (Nacach, 2020, 21). Idea que es conectada de forma intertextual, como si de un diálogo entre relatos de ficción se tratara, con las palabras de Iwasaki en el manual: "Aquel último salto narratológico lo di después de jugar un partido de fútbol donde fui sustituido de mala manera por un rústico entrenador que sin querer me dio un gran consejo: '¿Por qué no te dedicas a narrar, carajo?'. Y en eso estoy". (Cobo-Durán \& Lozano Delmar, 2020, 12).

En definitiva, el libro Narrativa(s) en ficción televisiva y cinematográfica consigue, a través de un estudio pormenorizado de la bibliografía esencial clásica y también actual, construir un manual asequible y sintetizado tanto como apoyo a la docencia como para cualquier tipo de lector/a que quiera enriquecerse y aprender sobre la temática. 


\section{REFERENCIAS}

Bordwell, D. (1996). La narración en el cine de ficción (1 $1^{\text {a }}$ ed.). Barcelona, España: Paidós Comunicación.

Cobo-Durán, S., \& Lozano Delmar, J., (2020). Narrativa(s) en ficción televisiva y cinematográfica. ( ${ }^{1}$ ed.). Sevilla, España: Readuck.

Greimas, A.J., (1983). La semiótica del texto: ejercicios prácticos: análisis de un cuento de Maupassant. Barcelona: Paidós.

Nacach, P., (2020). Amor maestro. Instrucciones de uso. (1 ${ }^{\text {a }}$ ed.). Barcelona, España: Anagrama. 